\title{
Opportunities for Municipal Low-grade Waste Heat Recovery and Potential Applications in Canada's Remote Communities
}

\author{
Jean Duquette \\ Department of Mechanical and Aerospace Engineering \\ Carleton University, Canada \\ jean.duquette@carleton.ca
}

Approximately $69 \%$ of the world's primary energy use by end use in the residential, commercial, industrial, and electricity generation sectors is lost to the environment in the form of waste heat. About half of this heat is emitted at a temperature that is below $100^{\circ} \mathrm{C}$ via building-based exhaust and effluent streams. Although waste heat in this temperature range is normally considered to be low-grade and of limited use, a significant portion can be recovered and put to a useful purpose using a district energy grid. A district energy grid is a centralized energy management system built around a network of buried pipes that permits the distribution of thermal energy from sources to loads.

In the first part of this talk, the role of district energy grids in improving overall municipal energy system efficiency will be presented. A number of low-grade waste heat recovery technologies will be described, and their integration in a number of unique district energy system configurations will be discussed. In the second part of this talk, a current project taking place in a rural northern Ontario community will be presented where district-level heat recovery technologies and systems are being considered for implementation. An overview of the technical, economic, and environmental impacts will be given, and the potential benefits of applying a similar energy system model in other remote communities located throughout Canada will also be discussed. 